\title{
ÚNG DỤNG TRAO ĐỔI OXY QUA MÀNG NGOÀI CƠ THỂ TRONG HỔI SỨC PHẪU THUẬT TIM
}

Nguyễn Phan Tú Uyên*, Nguyêen Thị Tuyết Lan*, Trần Quyết Tiến*

\section{TÓM TĂT}

Từ năm 2013- 2017 có 25 bệnh nhân được đặt $\mathrm{ECMO}$ và $\mathrm{VAD}$, riêng năm 20152017 có 20 bệnh nhân được đặt ECMO, trong đó 1 bệnh nhân chuyển viện ra nước ngoài trong quá trình điều trị. Trong số 19 bệnh nhân còn lại được tiếp tục theo dõi có 8 bệnh nhân cai ECMO thành công (42.1\%), 6 bệnh nhân xuất viện ổn định $(31.58 \%), 13$ bệnh nhân tử vong trong thời gian nằm viện do nhiều nguyên nhân khác nhau (68.42\%). Chỉ định đặt ECMO chủ yếu cho bệnh nhân suy tim sau phẫu thuật bắc cầu mạch vành do nhồi máu cơ tim $(14$ bệnh nhân). Các biến chứng thường gặp ở những bệnh nhân có đặt ECMO là nhiễm trùng, suy thận, suy gan, xuất huyết, thiếu máu chi, ...Phương tiện hỗ trợ tuần hoàn nâng caoECMO ra đời là một bước tiến mới trong lĩnh vực hồi sức tim mạch cũng như phẫu thuật tim, đã mang lại một cơ hội sống mới cho những bệnh nhân suy tim nặng kháng trị với những điều trị thông thường, cũng là bước đệm giúp bệnh nhân có thể chờ đợi biện pháp điều trị cuối cùng là ghép tim.

Tù khóa: Trao đổi oxy qua màng ngoài cơ thể (ECMO)

\section{SUMMARY}

\section{APPLYING THE ADVANCED CIRCULATION SUPPORT DEVICES FOR RESUSCITTATION IN CARDIAC SURGERY}

ABSTRACT

From 2013 to 2017,25 patients received
ECMO and VAD, especialy in 2015- 2017, 20 patients received ECMO, 1 patient was transfered abroad. Among 19 patients followed up, 8 patients were weaned ECMO successfully $(41.16 \%), 6$ patients got better and were discharged stably (31.68\%); in-hospital mortality was $68.42 \%$. The main indication of ECMO was cardiogenic shock after cardiac surgeries. The common complications of ECMO were sepsis, renal failure, hepatic failure, bleeding, leg ischemia..., The invention of advanced circulation support devices marked an obvious advance in cardiac resuscitation and cardiac surgery. That gave patients with refractory cardiac shock new chances to be rescued and wait for heart transplantation.

Key words: ECMO (Extracorporeal membrane oxygenation)

\section{I. ĐẶT VẤN ĐỀ}

Suy tim là tình trạng bệnh lý trong đó với áp lực đổ đầy thất bình thường tim không đủ khả năng bơm một lượng máu mang oxy và các chất biến dưỡng cho nhu cầu của cơ thể. Có thể nói suy tim là hậu quả cuối cùng của các bệnh tim bẩm sinh hoặc mắc phải, có thể xảy ra ở cả trẻ em hoặc người lớn. Năm 2015, trên thế giới có khoảng 26 triệu người mắc bệnh, ở các nước phát triển tỷ lệ mắc bệnh suy tim là $1-2 \%$ trong dân số người trưởng thành ${ }^{[4]}$. Suy tim tăng theo

\footnotetext{
* Trung tâm tim mạch, Bệnh viện Chơ Rã̃y Ngườ chịu trách nhiệm khoa học: PGS.TS. Trần Quyết Tiến Ngày nhận bài: 15/07/2018 - Ngày Cho Phép Đăng: 20/07/2018 Phản Biện Khoa học: PGS.TS. Đặng Ngocc Hùng GS.TS. Lê Ngọc Thành
} 
tuổi và là một trong những nguyên nhân nhập viện hàng đầu ở người trên 65 tuổi ${ }^{[6]}$.

Ngày nay với sự phát triển của y học, các biện pháp điều trị suy tim ngày càng được hoàn thiện và nâng cao: biện pháp không dùng thuốc, biện pháp dùng thuốc, phẫu thuật tim, đặt bóng đối xung động mạch chủ (IABP), tuần hoàn ngoài cơ thể (ECMO), thiết bị hỗ trợ thất (VAD), ghép tim. Đặc biệt các phương tiện hỗ trợ tuần hoàn ngày càng được sử dụng nhiều hơn và hiệu quả hơn trong điều trị suy tim giúp cứu sống bệnh nhân cũng như góp phần cải thiện chất lượng cuộc sống.

Các nghiên cứu cho thấy có 1-6\% bệnh nhân sốc tim sau khi được phẫu thuật tái tưới máu hoặc thay van tim, 0,5-1,5\% bệnh nhân không đáp ứng với thuốc vận mạch và bóng dội ngược động mạch chủ ${ }^{[1],[2],[E r r o r ! ~ R e f e r e n c e ~ s o u r c e ~ n o t ~}$ found.]. Tình trạng sốc tim sau phẫu thuật tim có thể xảy ra ở những bệnh nhân chức năng tim bình thường hoặc suy giảm trước đó, lúc này các phương tiện hỗ trợ tuần hoàn nâng cao giúp tưới máu các cơ quan nội tạng, giúp cơ tim được nghỉ ngơi và có thời gian hồi phục đã mang lại một hy vọng sống mới cho bệnh nhân ${ }^{[3]}$.

Hiện nay, đi cùng sự phát triển của $\mathrm{y}$ học thế giới, Bệnh viện Chợ Rẫy đã sử dụng các phương tiện hỗ trợ tuần hoàn cho bệnh nhân suy tim nặng. Từ năm 2010, tại khoa Hồi sức - Phẫu thuật tim bóng dội ngược động mạch chủ đã bắt đầu được đặt cho những bệnh nhân bệnh mạch vành nặng có suy tim và đau ngực nhiều. Năm 2013 chúng tôi tiếp tục sử dụng thiết bị trao đổi oxy qua màng ngoài cơ thể và dụng cụ hỗ trợ thất cho bệnh nhân suy tim không đáp ứng điều trị nội khoa. Để đánh giá lợi ích của việc ứng dụng các phương tiện kỹ thuật cao trong hồi sức phẫu thuật tim đặc biệt là thiết bị trao đổi oxy qua màng ngoài cơ thể, chúng tôi quyết định thực hiện nghiên cứu đánh giá kết quả bước đầu sử dụng thiết bị trao đổi oxy qua màng ngoài cơ thể tại khoa Hồi Sức - Phẫu Thuật Tim, Bệnh viện Chợ Rẫy.

\section{II. ĐỐI TƯợNG VÀ PHƯƠNG PHÁP} NGHIÊN CỨU

2.1. THIÊT KẾ NGHIÊN CưU: Hồi cứu, báo cáo hàng loạt ca.

\section{2. ĐỐI TƯợNG NGHIÊN CÚUU}

Dân số mục tiêu: Bệnh nhân đã được sử dụng ECMO.

Dân số nghiên cứu: Bệnh nhân đã được sử dụng ECMO tại khoa Hồi sức - Phẫu thuật tim Bệnh viện Chợ Rẫy.

Tiêu chuẩn chọn bệnh: Bệnh nhân đã được sử dụng ECMO tại khoa Hồi Sức - Phẫu Thuật Tim, Bệnh viện Chợ Rẫy.

Tiêu chuẩn loại trù: Không đủ dữ liệu nghiên cứu.

$\boldsymbol{C} \tilde{\boldsymbol{\sigma}} \boldsymbol{m} \tilde{a} u$ : Lấy tất cả các trường hợp thỏa tiêu chí chọn bệnh.

2.3. XỬ LÝ SỐ LIỆU : Các thuật toán thống kê y học (phần mềm SPSS).

\section{KÊT QUẢ NGHIÊN CÚU}




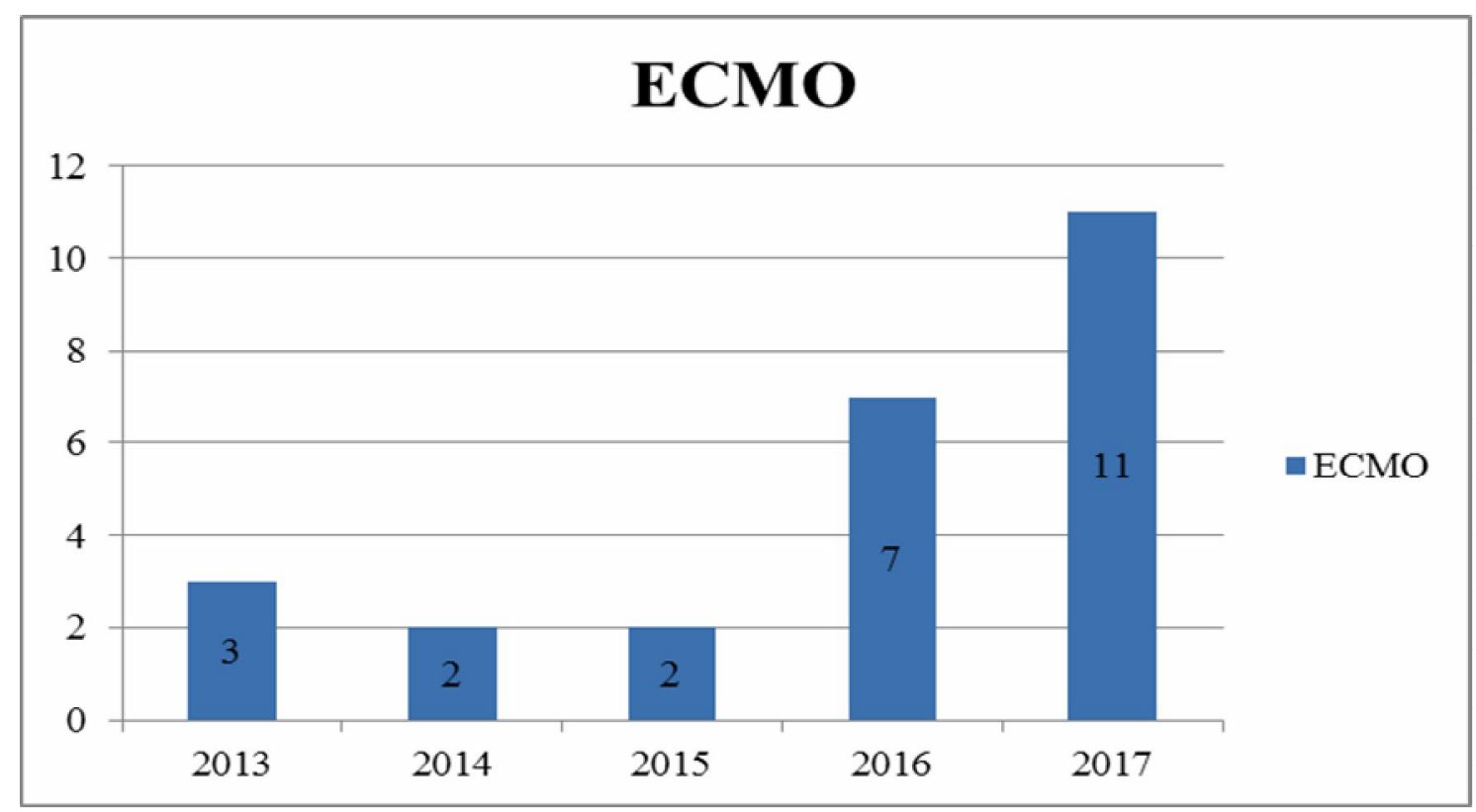

Biểu đồ 3.1: Số lựng bệnh nhân đực sử dụng ECMO

Nhận xét: Số lượng bệnh nhân được sử dụng ECMO ngày càng tăng

\subsection{BỆNH CƠ BẢN CẦN SỬ DỤNG ECMO TỬ 2015 - 2017}

Bảng 3.1: Bệnh co bản cần sủ dụng dụng cụ hố trọ tuần hoàn

\begin{tabular}{|l|l|l|}
\hline Bệnh cơ bản & Tần số & Tỉ lệ (\%) \\
\hline Nhồi máu cơ tim & 14 & 70 \\
Bệnh van tim & 4 & 20 \\
Tim bẩm sinh & 2 & 10 \\
\hline
\end{tabular}

Nhận xét: bệnh cơ bản cần được hỗ trợ tuần hoàn đa số là bệnh mạch vành

\subsection{THỜI GIAN SỬ DỤNG ECMO}

Bảng 3.2: thời gian sủ dụng phuơng tiện hỗ trọ tuần hoàn

\begin{tabular}{|l|l|}
\hline Phương tiện & Thời gian (ngày) \\
\hline Trao đồi oxy qua màng ngoài cơ thể (ECMO) & 13 ngày ( 3-24) \\
\hline
\end{tabular}

Nhận xét: thời gian sử dụng tuần hoàn ngoài cơ thể trung bình 13 ngày, dài nhất 24 ngày, ngắn nhất 3 ngày

\subsection{TỈ LÊ TỬ VONG}

Từ năm 2015 đến 2017 có 20 bệnh nhân đặt ECMO, trong đó có 1 bệnh nhân chuyển ra nước ngoài khi đang sử dụng ECMO nên không theo dõi tiếp tục quá trình điều trị, trong 19 bệnh nhân còn lại có 8 bệnh nhân cai ECMO thành công (chiếm tỉ lệ 42.1\%) và 6 bệnh nhân xuất viện trong 
tình trạng ổn định (chiếm tỉ lệ $31.58 \%$ ), 13 bệnh nhân diễn tiến nặng và thân nhân xin về (chiếm tỉ lệ $68.42 \%)$.

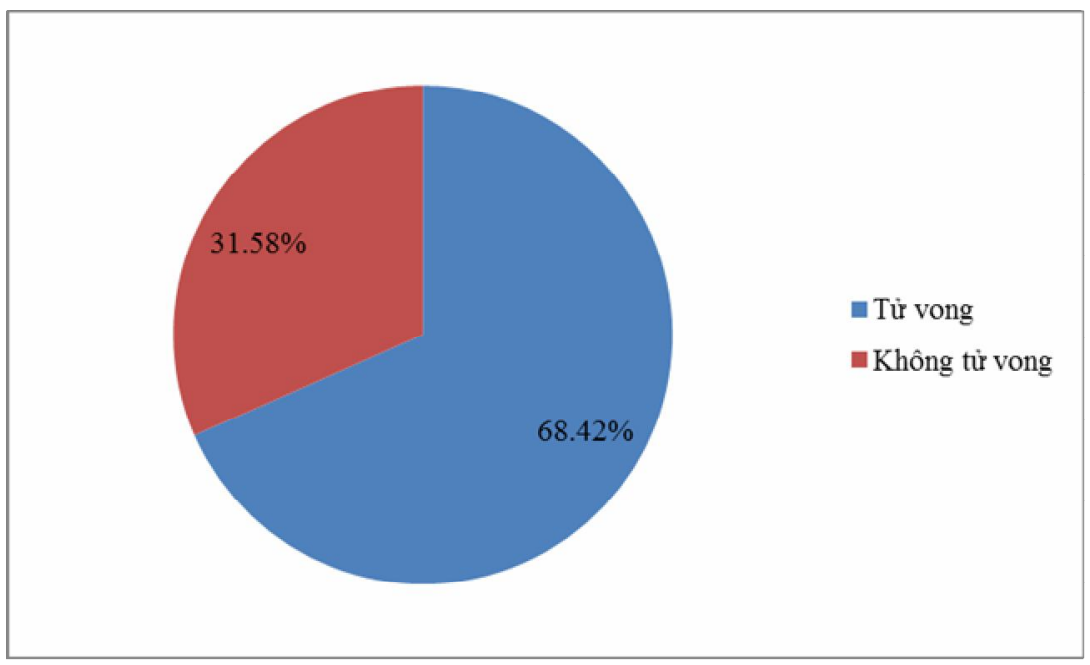

Biểu đồ 3.2: Tỉ lệ tử vong ở bệnh nhân đự̛c sử dụng ECMO

Nhận xét: Tỉ lệ tử vong ở bệnh nhân được sử dụng ECMO tương đối cao

\subsection{NGUYÊN NHÂN TỦ VONG 2015 - 2017}

Bảng 3.3: Nguyên nhân tử vong ở bệnh nhân sủ dụng dụng cu hỗ trọ tuần hoàn

\begin{tabular}{|l|c|c|}
\hline Nguyên nhân & Tần số & Tỉ lệ (\%) \\
\hline Suy 2 thất, suy đa cơ quan & 5 & 38.46 \\
\hline Chảy máu & 3 & 23.08 \\
\hline Tắc cầu vành & 2 & 15.38 \\
\hline Viêm phổi do Klebsiella và Candida albicans & 2 & 15.38 \\
\hline Tăng áp phổi & 1 & 7.7 \\
\hline
\end{tabular}

Nhận xét: nguyên nhân tử vong chủ yếu do tình trạng suy tim quá nặng.

\subsection{BIẾN CHÚNG}

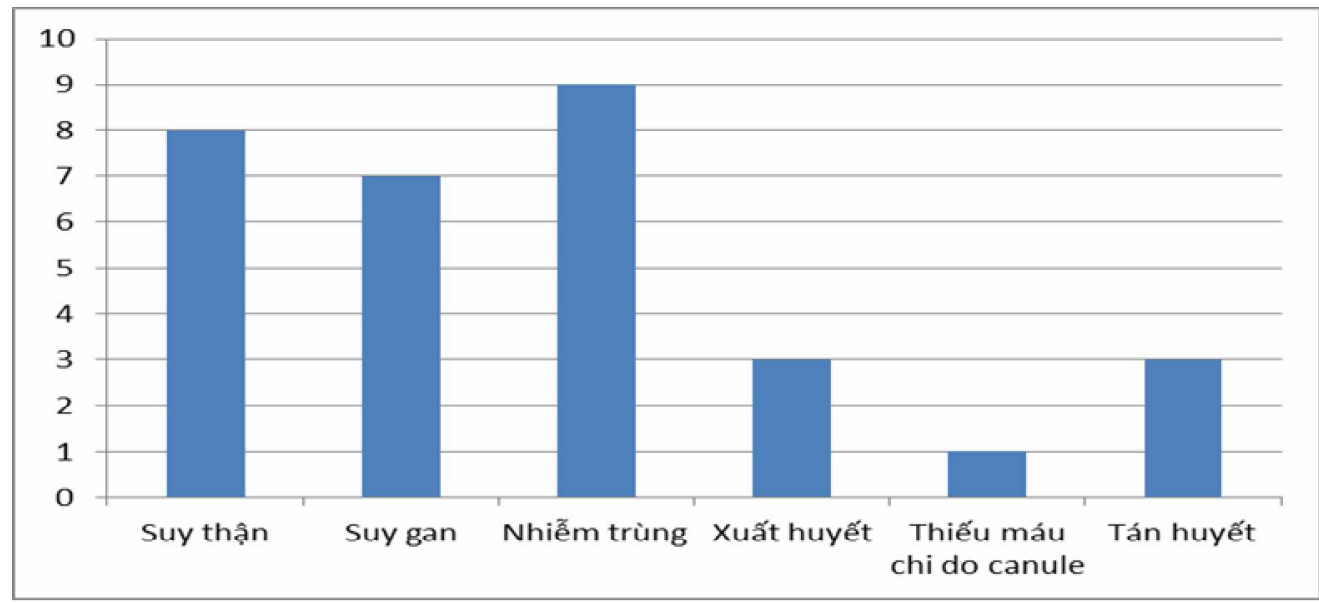

Biểu đồ 3.4: Tần suất biến chứng ở bệnh nhân sủ̉ dụng ECMO 
Nhận xét: Biến chứng gặp nhiều nhất là tình trạng nhiễm trùng nặng

\section{BÀN LUẬN}

Phương tiện hỗ trợ tuần hoàn đầu tiên được sử dụng tại khoa Hồi Sức - Phẫu Thuật Tim, Bệnh viện Chợ Rẫy là bóng dội ngược động mạch chủ với số lượng chỉ 2 ca trong năm 2010, nhưng những năm sau đó số lượng bóng được đặt đã tăng dần. Điều này cho thấy sự cố gắng nổ lực hết mình của đội ngũ bác sĩ và nhân viên y tế tại khoa vì bóng dội ngược khi mới có là một dụng cụ hồi sức hoàn toàn mới lạ đòi hỏi phải có kiến thức và kỹ năng thuần thục để sử dụng, ngoài việc chọn lựa thời điểm chỉ định đặt bóng thích hợp chúng ta còn phải biết theo dõi hoạt động của máy một cách chặt chẽ, tránh để những biến chứng không mong muốn xảy ra. Mặc dù việc đặt bóng có ca thành công cũng có ca thất bại nhưng chúng tôi vẫn không nản chí vẫn quyết tâm rút kinh nghiệm để hoàn thiện hơn cho những trường hợp cần đặt bóng sau này, dần dần tỉ lệ đặt bóng thành công cho bệnh nhân ngày càng tăng, chúng tôi càng mạnh dạn hơn trong chỉ định đặt bóng dội ngược động mạch chủ, khảo sát sơ bộ trên 42 bệnh nhân đặt IABP năm 2016 ghi nhận có 17 bệnh nhân bệnh vẫn diễn tiến nặng (chiếm tỉ lệ $40 \%$ ). Từ đó đòi hỏi các bác sĩ cần áp dụng các phương pháp hỗ trợ tuần hoàn nâng cao hơn IABP như ECMO. Vì vậy tỉ lệ sử dụng ECMO trong hồi sức tim mạch ngày càng tăng và đã đạt được những thành quả bước đầu.

Trong những năm đầu ứng dụng ECMO, số lượng bệnh nhân không cao vì đây là phương tiện hồi sức chuyên sâu, kỹ thuật cao, đòi hỏi không những máy móc, dụng cụ mà còn phải có sự phối hợp nhịp nhàng giữa các nhân viên y tế từ phẫu thuật viên, bác sĩ hồi sức, gây mê, chạy máy đến điều đưỡng để tạo thành một ekip hoàn chỉnh ${ }^{[6]}$. Ngoài ra vấn đề chi phí khá cao là một trở ngại khi thực hiện vì không phải bệnh nhân nào cũng có khả năng.

Trong số 19 ca bệnh nhân cần sử dụng ECMO từ 2015 - 2017, có đến 14 ca bệnh lý cơ bản là nhồi máu cơ tim, tổn thương mạch vành rất nặng ảnh hưởng lên chức năng tim làm suy tim nặng khó hồi phục, trong đó có 1 ca bệnh cơ bản rất nặng vừa nhồi máu cơ tim vừa phình động mạch chủ cho thấy việc sử dụng tuần hoàn ngoài cơ thể là hợp lý và rất cần thiết cho bệnh nhân.

Trao đổi oxy qua màng ngoài cơ thể tại khoa Hồi Sức - Phẫu Thuật Tim, Bệnh viện Chợ Rẫy được đặt cho đối tượng bệnh cả trẻ em và người lớn, đa số là để hỗ trợ tim sau phẫu thuật tim. Bệnh thường nặng và có nhiều tổn thương phối hợp, cụ thể một bệnh nhân 14 tuổi suy tim cấp - sốc tim trên nền viêm cơ tim tiến triển cần đặt ECMO và sau đó đặt dụng cụ hỗ trợ thất, một bệnh nhi 3 tuổi được phẫu thuật sửa chữa triệt để tứ chứng Fallot, sau mổ tim co bóp kém, cai máy tim phổi nhân tạo khó khăn, huyết áp dao động, vận mạch sử dụng liều cao, bệnh nhi được đặt $\mathrm{ECMO}$ và để hở xương ức, một bệnh nhân 56 tuổi bị nhồi máu cơ tim Killip IV và phình quai động mạch chủ ngực dạng túi được phẫu thuật bắc cầu mạch vành, cắm lại tất cả các nhánh nuôi não va đặt stent graft động mạch chủ ngực dưới sự hỗ trợ ECMO, một bệnh nhân viêm nội tâm mạc 
nhiễm trùng, áp xe van động mạch chủ và rách van động mạch chủ, bệnh nhân ngưng tim trước phẫu thuật và được đặt ECMO phối hợp khi phẫu thuật tim, các bệnh nhân còn lại đều bị nhồi máu cơ tim cấp Killip IV kèm theo các biến chứng nặng như thủng vách liên thất, hở van 2 lá nặng,... được phẫu thuật bắc cầu mạch vành và giải quyết các tình trạng nặng đi kèm sau đó đều cần đặt máy ECMO để hỗ trợ. Năm 2017 có 2 trường hợp nhồi máu cơ tim nặng được đặt ECMO trước mổ do tình trạng suy tim quá nặng không thích hợp phẫu thuật ngay mà cần phải có thời gian để cơ tim được nghỉ ngơi và hồi phục, từ đó cho thấy chúng ta có thể ứng dụng ECMO trong những trường hợp cấp cứu hồi sinh tim phổi cho bệnh nhân không hiệu quả - ECPR (Extracorporeal Cardiopulmonary resuscitation).

Tất cả các bệnh nhân được đặt ECMO tại khoa Hồi sức - Phẫu thuật tim Bệnh viện Chợ Rẫy đều loại trung tâm và $\mathrm{V}-\mathrm{A}$. Thời gian sử dụng ECMO trung bình 13 ngày (từ 03 đến 24 ngày) là tương đối dài so với các trường hợp viêm cơ tim đơn thuần hoặc chỉ hỗ trợ phổi vì những bệnh nhân này đa số đều phải trải qua một cuộc phẫu thuật tim lớn kéo dài tim bị tổn thương nặng kèm tình trạng suy tim trước mổ, khả năng và thời gian hồi phục rất khó đoán trước.

Tỉ lệ cai máy ECMO thành công từ năm 2015- 2017 chiếm 42.1\%. Theo tác giả Rastan $\mathrm{AJ}$ và cộng sự tổng hợp 517 ca bệnh nhân sử dụng ECMO ở bệnh nhân sốc tim sau phẫu thuật tim, tỉ lệ cai ECMO thành công là 31$60 \%$ [2], tác giả Doll N và cộng sự ghi nhận tỉ lệ cai ECMO thành công là $60 \%$ [1]. Tỉ lệ tử vong ở bệnh nhân suy tim nặng được đặt ECMO tại khoa Hồi sức - Phẫu thuật tim từ năm 2015- 2017 chiếm $68.42 \%$. Theo tác giả Rastan và cộng sự tỉ lệ tử vong trong bệnh viện của những bệnh nhân đặt ECMO là 59$84 \%$ [2]. Như vậy kết quả nghiên cứu của chúng tôi tương đồng với các nghiên cứu trên thế giới. Đa số bệnh nhân có bệnh nền rất nặng, hỗ trợ tuần hoàn thường phải sử dụng trong bối cảnh cấp cứu, có trường hợp phải sử dụng cùng lúc 2 hoặc 3 phương tiện hỗ trợ. Tuy nhiên trong số các bệnh nhân suy tim nặng, sốc tim với tỉ lệ tử vong gần như $100 \%$ chúng ta có thể cứu được gần $30 \%$ bệnh nhân nhờ vào phương tiện hỗ trợ tuần hoàn nâng cao, điều đó cho thấy việc áp dụng các phương tiện hỗ trợ tuần hoàn bước đầu đã cho kết quả khả quan và là nền tảng, động lực để chúng tôi tiếp tục phát huy việc ứng dụng các phương tiện này trong tương lai để nâng cao tỉ lệ cứu sống bệnh nhân.

Trong nghiên cứu của chúng tôi mặc dù đã được sử dụng phương tiện hỗ trợ tuần hoàn nhưng nguyên nhân tử vong chủ yếu là suy hai thất tiến triển đến suy đa cơ quan là $4 / 12 \mathrm{ca}$ chiếm tỉ lệ 33,33\% cho thấy tình trạng suy tim và tổn thương tim của bệnh nhân rất nặng, không có khả năng hồi phục. Bên cạnh đó tình trạng nhiễm trùng và các biến chứng do nằm lâu sau phẫu thuật cũng như sau đặt máy hỗ trợ tuần hoàn cũng góp phần vào nguyên nhân gây tử vong cho bệnh nhân ${ }^{[4],[5]}$.

Tất cả bệnh nhân được đặt ECMO đều có biến chứng, nhiều nhất là biến chứng nhiễm trùng nặng có thể do tất cả đều được đặt ECMO trung tâm trong thời gian dài, tổng trạng bệnh 
nhân kém, phẫu thuật, thủ thuật xâm lấn nhiều, thở máy kéo dài nên nguy cơ nhiễm trùng cao. Ngoài ra các biến chứng suy gan, suy thận, chảy máu, xuất huyết, thiếu máu chi cũng thường gặp do giảm lưu lượng tuần hoàn, sử dụng nhiều loại thuốc hỗ trợ như vận mạch, kháng sinh, kháng đông...

Như vậy qua nghiên cứu này chúng ta phần nào khái quát được tình hình sử dụng thiết bị trao đổi oxy qua màng ngoài cơ thể tại khoa Hồi sức - Phẫu thuật tim bệnh viện Chợ Rẫy, đây là kỹ thuật mới, hiện đại mở ra cơ hội cứu sống cho các bệnh nhân với bệnh lý tim mạch nặng nề và phức tạp hơn mà trước đây các phương pháp điều trị nội và ngoại khoa cổ điển không cứu chữa được. Đây cũng là các phương tiện chuyên sâu giúp cũng cố, hỗ trợ phát triển hơn nữa lãnh vực phẫu thuật tim, giúp các bác sĩ mạnh dạn hơn đối với những trường hợp mà trước đây được cho là quá chỉ định phẫu thuật.

\section{KẾT LUẬN}

Qua nghiên cứu này chúng tôi rút ra những kết luận sau:

- ECMO là phương tiện hồi sức kỹ thuật cao được sử dụng tại khoa Hồi Sức - Phẫu Thuật Tim từ năm 2013.

- Tỉ lệ bệnh nhân được đặt ECMO tăng dần qua các năm.

- Bệnh cơ bản cần đặt ECMO chủ yếu là nhồi máu cơ tim.

- Thời gian sử dụng ECMO trung bình là 13 ngày

- Tỉ lệ tử vong ở những bệnh nhân được sử dụng ECMO tương đối cao chiếm $68.42 \%$

- Nguyên nhân tử vong ở những bệnh nhân được sử dụng ECMO chủ yếu do suy 2 thất, suy đa cơ quan

- Biến chứng gặp nhiều nhất ở những bệnh nhân được sử dụng ECMO là nhiễm trùng nặng, suy gan, suy thận, xuất huyết, thiếu máu chi.

- Phương tiện hỗ trợ tuần hoàn nâng cao ra đời là một bước tiến mới trong lĩnh vực hồi sức tim mạch cũng như phẫu thuật tim, đã mang lại một cơ hội sống mới cho những bệnh nhân suy tim nặng kháng trị với những điều trị thông thường, cũng là bước đệm giúp bệnh nhân có thể chờ đợi biện pháp điều trị cuối cùng là ghép tim.

\section{TÀI LIỆU THAM KHẢO}

1. Doll N, Kiaii B, et al, 2004, "FiveYear results of 219 consecutive patients treated with extracorporeal membrane oxygenation for refractory postoperative cardiogenic shock", The Annals of Thoracic Surgery, Volume 77, Issue 1, January 2004, Pages 151-157

2. Rastan AJ, Dege A, et al, 2010, "Early and late outcomes of 517 consecutive adult patients treated withextracorporeal membrane oxygenation for refractory postcardiotomy cardiogenic shock", The Journal of Thoracic and Cardiovascular Surgery, Volume 139, Issue 2, February 2010, Pages 302-311.e1

3. Bermudez CA, Rocha RV, et al, 2011, "Extracorporeal Membrane Oxygenation for Advanced Refractory Shock in Acute and 
Chronic CardiomyopathyOriginal Research Article", The Annals of Thoracic Surgery, Volume 92, Issue 6, December 2011, Pages 2125-2131.

4. Kumar TKS, Zurakowski D, et al, 2010, "Extracorporeal membrane oxygenation in postcardiotomy patients: Factors influencing outcomeOriginal Research Article", The Journal of Thoracic and Cardiovascular Surgery, Volume 140, Issue 2, August 2010, Pages 330-336.e2
5. Meng-Yu Wu, Pyng-Jing Lin, et al, 2010, "Using extracorporeal life support to resuscitate adult postcardiotomy cardiogenic shock: Treatment strategies and predictors of short-term and midterm survival", Original Research Article, Resuscitation, Volume 81, Issue 9, September 2010, Pages 1111-1116.

6. Khan MH, Corbett BJ, et al, 2014, "Mechanical circulatory support in acute cardiogenic shock", F1000Prime Rep. 2014; 6: 91. 